\title{
Comparison of Path Planning Algorithms for Extinguishing Forest Fires with A Algorithm
}

\author{
M.P.Sivaram Kumar \\ Research Scholar/CSE \\ B S Abdur Rahman University \\ Vandalur, Chennai-48
}

\author{
S.Rajasekaran \\ Professor/Mathematics \\ B S Abdur Rahman University \\ Vandalur, Chennai-48
}

\begin{abstract}
The scope of this paper is to simulate, analyze and compare path planning algorithms for mobile robots to move smoothly in a collision free grid based static environment for extinguishing forest fires with $\mathrm{A}^{*}$ Algorithm. The algorithms are compared in terms of parameters such as cost of the path, execution time of the algorithm, obstacle position and number of obstacles. We have taken two algorithms for comparison with $\mathrm{A}^{*}$ algorithm and the simulation is carried out using MATLAB .The results obtained indicate that path planning algorithms for Extinguishing forest fires are better choice than $\mathrm{A}^{*}$ Algorithm as time taken for executing (i.e. finding Paths) these algorithms is less than the time taken by the $A^{*}$ Algorithm in the same configuration space .Further more distance based algorithm produces path, the cost of which is less or same as $\mathrm{A}^{*}$ in most of the cases and line based algorithm produced path the cost of which is more in eighty percent of the cases for the samples we have taken.
\end{abstract}

\section{General Terms}

Path Planning Algorithm

\section{Keywords}

$\mathrm{A}^{*}$ Algorithm, execution time, path cost, MATLAB

\section{INTRODUCTION}

Path Planning is a Fundament task in Robotics whether the robot is employed in static or dynamic environment. There are several path planning algorithms which have been proposed in the literature for static and dynamic environments $[1,2]$. Path Planning approaches have been applied to diverse fields. But no previous work has been found in the literature about path planning algorithms for extinguishing forest fires, until the authors proposed such algorithms. Deterministic path planning are more preferred to probabilistic path planning when the dimensionality of path planning is low because they provide bounds on the quality of the solution[3]. Since the geographical location information about forest can be available, the Grid based deterministic algorithms is used in all our works and we have limited the dimensionality to two. $\mathrm{A}^{*}$ Algorithm is a well known method to obtain an optimal path between nodes, where the nodes may be the cells or elements of the grid used to represent the environment[3].This is the fundamental reason for choosing $\mathrm{A}^{*}$ Algorithm for comparing the performance with our algorithms. The rest of the paper is organized as follows: Section 2 Briefly reviews our algorithms and $\mathrm{A}^{*}$ Algorithm. Section 3 presents the simulation results while section 4 concludes the paper.

\section{Review of Algorithms}

\subsection{Direction based algorithm}

In [4] we have developed the algorithm supported by Matrix based deployment of sensor nodes. This is shown below in Figure 1. The path planning of the Actor is done in incremental steps by taking into consideration the start position coordinates

\begin{tabular}{|c|c|c|c|}
\hline$(1,1)$ & $(1,2)$ & $\cdots$ & $(1, \mathrm{n})$ \\
\hline$(2,1)$ & $(2,2)$ & $\cdots$ & $(2, \mathrm{n})$ \\
\hline$(3,1)$ & $(3,2)$ & $\ldots$ & $(3, \mathrm{n})$ \\
\hline$\cdot$ & $\cdot$ & $\cdot$ & $\cdot$ \\
\hline$\cdot$ & $\cdot$ & $\cdot$ & $\cdot$ \\
\hline$(\mathrm{m}-1,1)$ & $(\mathrm{m}-1,2)$ & $\cdots$ & $(\mathrm{m}-1, \mathrm{n})$ \\
\hline$(\mathrm{m}, 1$ & $(\mathrm{m}, 2)$ & $\cdots$ & $(\mathrm{m}, \mathrm{n})$ \\
\hline
\end{tabular}

Figure 1 Matrix based deployment of sensor nodes.

and goal position coordinates. Since in this work we are using matrix based coordinates for the grid, the determination of direction of in which the actor has to move presented in [5] is modified and calculated using the table 1 .The Actor can move in any of the eight neighborhood cells [6] as shown in Figure 2. After determining which cell the robot has to move then it will check for the presence of the obstacle in the cell. This is performed by checking the array of cells. If the value of the cell is one then it means the cell contains an obstacle otherwise no obstacle is present in the cell. If no obstacle is present in the next cell then the process is repeated to find the next cell. If obstacle is present then it will find the free adjacent cell by calling the procedure freespacesearch. It will return the cell which will be closer to the destination cell. Each time it calculates the next cell the corresponding coordinate will be stored in the memory. The whole process is repeated till the next cell computed is the destination cell. 
Table 1 Matrix based deployment of sensor nodes

\begin{tabular}{|c|c|l|}
\hline S.no & Condition of coordinates & $\begin{array}{l}\text { Direction the } \\
\text { Actor has to } \\
\text { move }\end{array}$ \\
\hline 1. & $\left(\mathrm{x}_{\mathrm{s}}-\mathrm{x}_{\mathrm{g}}=0\right)$ and $\left(\mathrm{y}_{\mathrm{s}}-\mathrm{y}_{\mathrm{g}}<0\right)$ & Right \\
\hline 2. & $\left(\mathrm{x}_{\mathrm{s}}-\mathrm{x}_{\mathrm{g}}>0\right)$ and $\left.\left(\mathrm{y}_{\mathrm{s}}-\mathrm{y}_{\mathrm{g}}\right)<0\right)$ & $\begin{array}{l}\text { Diagonal Up } \\
\text { Right }\end{array}$ \\
\hline 3. & $\left(\mathrm{x}_{\mathrm{s}}-\mathrm{x}_{\mathrm{g}}>0\right)$ and $\left.\left(\mathrm{y}_{\mathrm{s}}-\mathrm{y}_{\mathrm{g}}\right)=0\right)$ & Up \\
\hline 4. & $\left(\mathrm{x}_{\mathrm{s}}-\mathrm{x}_{\mathrm{g}}>0\right)$ and $\left.\left(\mathrm{y}_{\mathrm{s}}-\mathrm{y}_{\mathrm{g}}\right)>0\right)$ & Diagonal Up Left \\
\hline 5. & $\left(\mathrm{x}_{\mathrm{s}}-\mathrm{x}_{\mathrm{g}}=0\right)$ and $\left.\left(\mathrm{y}_{\mathrm{s}}-\mathrm{y}_{\mathrm{g}}\right)>0\right)$ & Left \\
\hline 6. & $\left(\mathrm{x}_{\mathrm{s}}-\mathrm{x}_{\mathrm{g}}<0\right)$ and $\left.\left(\mathrm{y}_{\mathrm{s}}-\mathrm{y}_{\mathrm{g}}\right)>0\right)$ & $\begin{array}{l}\text { Diagonal Down } \\
\text { Right }\end{array}$ \\
\hline 7. & $\left(\mathrm{x}_{\mathrm{s}}-\mathrm{x}_{\mathrm{g}}<0\right)$ and $\left.\left(\mathrm{y}_{\mathrm{s}}-\mathrm{y}_{\mathrm{g}}\right)=0\right)$ & Down \\
\hline 8. & $\left(\mathrm{x}_{\mathrm{s}}-\mathrm{x}_{\mathrm{g}}<0\right)$ and $\left.\left(\mathrm{y}_{\mathrm{s}}-\mathrm{y}_{\mathrm{g}}\right)<0\right)$ & $\begin{array}{l}\text { Diagonal Down } \\
\text { Left }\end{array}$ \\
\hline & & \\
\hline
\end{tabular}

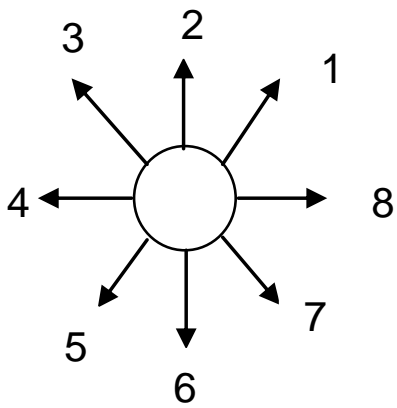

Figure 2 Direction in which an actor can move

\subsection{Line equation based algorithm}

In [7] a mathematical approach based path planning of actor which uses equation of a straight line passing through two points is proposed to extinguish forest fires. The algorithm presented in [8] is modified and presented in [7]. Forest domain is considered as a square area and is tessellated into $n$ $\mathrm{x} n$ cells (small squares) of desired size based on I quadrant as shown below in Figure 3. The Actor which performs actions similar to the actions performed by a robot is assumed to be available at one cell which is considered as one point and the cell in which fire occurs are considered as the second point. The equation of straight line is found out using these two points formula as shown below

$$
\frac{y-y 1}{y 2-y 1}=\frac{x-x 1}{x 2-x 1}---(1)
$$

\begin{tabular}{|c|r|r|r|r|}
\hline 0,4 & 1,4 & 2,4 & 3,4 & 4,4 \\
\hline 0,3 & 1,3 & 2,3 & 3,3 & 4,3 \\
\hline 0,2 & 1,2 & 2,2 & 3,2 & 4,2 \\
\hline 0,1 & 1,1 & 2,1 & 3,1 & 4,1 \\
\hline 0,0 & 1,0 & 2,0 & 3,0 & 4,0 \\
\hline
\end{tabular}

\section{Figure 3 Decomposition of forest based on First Quadrant}

Then after simplification of equation 1 by substituting the values of $(x 1, y 1)$ and $(x 2, y 2)$ we will get an equation of the form

$y=m x+c---(2)$

Then using the straight line equation (4) the sequence of intermediate cells between the cell where the Actor is available and the cell where the fire is occurred is computed and stored in memory by keeping the base value of $\mathrm{x}$ as the starting point $\mathrm{x}$-coordinate and then incrementing the value of $\mathrm{x}$ by 0.25 till the incremented value of $\mathrm{x}$ is same as the ending point $\mathrm{x}$-coordinate. Then a check is made for presence of obstacle in the intermediate cells. If there are obstacles present then a cell without obstacle and also nearer to obstacle cell is found out and replaced in the memory. Integrity check is performed to make sure that successive points are incremental points. i.e. whether the next point can be reached in one move. Then the sequence of points stored in the memory is used by the Actor to move to the cell where fire is occurred and after reaching that cell the actor will start to extinguish fire.

\section{$2.3 \mathrm{~A}^{*}$ algorithm}

The A* algorithm combines features of uniform-cost search and pure heuristic search to efficiently compute optimal solutions. A* algorithm is a best-first search algorithm in which the cost associated with a node is $f(n)=g(n)+h(n)$, where $g(n)$ is the cost of the path from the initial state to node $\mathrm{n}$ and $\mathrm{h}(\mathrm{n})$ is the heuristic estimate or the cost or a path from node $\mathrm{n}$ to a goal. Thus, $\mathrm{f}(\mathrm{n})$ estimates the lowest total cost of any solution path going through node $n$. At each point a node with lowest $f$ value is chosen for expansion. Ties among nodes of equal $f$ value should be broken in favor of nodes with lower $\mathrm{h}$ values. The algorithm terminates when a goal is chosen for expansion [9]. The program for $\mathrm{A}^{*}$ algorithm is written using the pseudo code presented in [10] and the pseudo code is shown below

1. Create a search graph $\mathrm{G}$, consisting solely of the start node, $\mathrm{n}_{\mathrm{o}}$. Put $\mathrm{n}_{\mathrm{o}}$ on a list called OPEN.

2. Create a list called CLOSED that is initially empty.

3. If OPEN is empty, exit with failure.

4. Select the first node on OPEN, remove it from OPEN, and put it on CLOSED. Called this node $n$.

5. If $\mathrm{n}$ is a goal node, exit successfully with the solution obtained by tracing a path along the pointers from $n$ to $n_{0}$ in $G$. (The pointers define a search tree and are established in Step 7.) 
6. Expand node $\mathrm{n}$, generating the set $\mathrm{M}$, of its successors that are not already ancestors of $\mathrm{n}$ in $\mathrm{G}$. Install these members of $\mathrm{M}$ as successors of $\mathrm{n}$ in $\mathrm{G}$.

7. Establish a pointer to $\mathrm{n}$ from each of those members of $\mathrm{M}$ that were not already in $\mathrm{G}$ (i.e., not already on either OPEN or CLOSED). Add these members of $M$ to OPEN. For each member, $\mathrm{m}$, of $\mathrm{M}$ that was already on OPEN or CLOSED, redirect its pointer to $\mathrm{n}$ if the best path to $\mathrm{m}$ found so far is through $\mathrm{n}$. For each member of $\mathrm{M}$ already on CLOSED, redirect the pointers of each of its descendants in $\mathrm{G}$ so that they point backward along the best paths found so far to these descendants.

8. Reorder the list OPEN in order of increasing $f$ values. (Ties among minimal $f$ values are resolved in favor of the deepest node in the search tree.)

9. Go to Step 3 .

\section{Simulation results}

The simulation is carried out using Matlab. For Analysis purpose we have taken the environment divided into $10 * 10$ grids. We have considered 50 different starting and end points. The direction based algorithm produced path which is less or same as that of the $\mathrm{A}^{*}$ algorithm for the environment with and without obstacles. But the line based algorithm produced path which is less or same for 80 percent of the samples for the environment without obstacles and only 20 percent for the environment with obstacles. The simulation results and graph are shown for single starting point and ending point. The starting and goal points for all the algorithms remain the same. The starting point is $(2,3)$ and the goal point is considered $(7,8)$. The simulation is carried out with and without obstacles. First Path is found out without obstacles. The sequence of intermediate points which makes the path without obstacle is noted. Next path finding with obstacles is performed in two phases. In Phase I the obstacles are placed in the intermediate points one by one for which path cost and execution time is noted. In Phase II the obstacles are kept one by one which collapses the path obtained in previous step. Graphs are also plotted using MS-Excel indicating the execution time (ET), path cost (PC) and number of obstacles. The simulation results are shown below.

\begin{tabular}{|l|l|l|l|l|l|l|}
\hline & \multicolumn{2}{|l|}{ A $^{*}$ algorithm } & \multicolumn{2}{|l|}{$\begin{array}{l}\text { Direction } \\
\text { based } \\
\text { algorithm }\end{array}$} & \multicolumn{2}{|l|}{$\begin{array}{l}\text { Line equation } \\
\text { based algorithm }\end{array}$} \\
\hline & ET & PC & ET & PC & ET & PC \\
\hline $\begin{array}{l}\text { Without } \\
\text { obstacle }\end{array}$ & 1.273 & 5 & 0.151 & 5 & 0.277 & 5 \\
\hline $\begin{array}{l}\text { With one } \\
\text { obstacle }\end{array}$ & 1.542 & 6 & 0.189 & 6 & 0.072 & 6 \\
\hline $\begin{array}{l}\text { With two } \\
\text { obstacle }\end{array}$ & 1.518 & 6 & 0.226 & 6 & 0.070 & 7 \\
\hline $\begin{array}{l}\text { With } \\
\text { three } \\
\text { obstacle }\end{array}$ & 1.547 & 6 & 0.231 & 6 & 0.076 & 8 \\
\hline $\begin{array}{l}\text { With four } \\
\text { obstacle }\end{array}$ & 1.580 & 6 & 0.238 & 6 & 0.074 & 9 \\
\hline
\end{tabular}

\begin{tabular}{|c|c|c|c|c|c|c|}
\hline & \multicolumn{2}{|c|}{$\mathrm{A}^{*}$ algorithm } & \multicolumn{2}{|c|}{$\begin{array}{l}\text { Direction } \\
\text { based } \\
\text { algorithm }\end{array}$} & \multicolumn{2}{|c|}{$\begin{array}{l}\text { Line equation } \\
\text { based } \\
\text { algorithm }\end{array}$} \\
\hline & ET & PC & ET & $\mathrm{PC}$ & ET & PC \\
\hline $\begin{array}{l}\text { With two } \\
\text { obstacle }\end{array}$ & 1.551 & 6 & 0.251 & 6 & .062 & 6 \\
\hline $\begin{array}{l}\text { With three } \\
\text { obstacle }\end{array}$ & 1.525 & 6 & 0.229 & 6 & .048 & 7 \\
\hline $\begin{array}{l}\text { With four } \\
\text { obstacle }\end{array}$ & 1.457 & 6 & 0.248 & 6 & .064 & 8 \\
\hline $\begin{array}{l}\text { With five } \\
\text { obstacle }\end{array}$ & 1.515 & 6 & 0.230 & 6 & .0516 & 9 \\
\hline
\end{tabular}
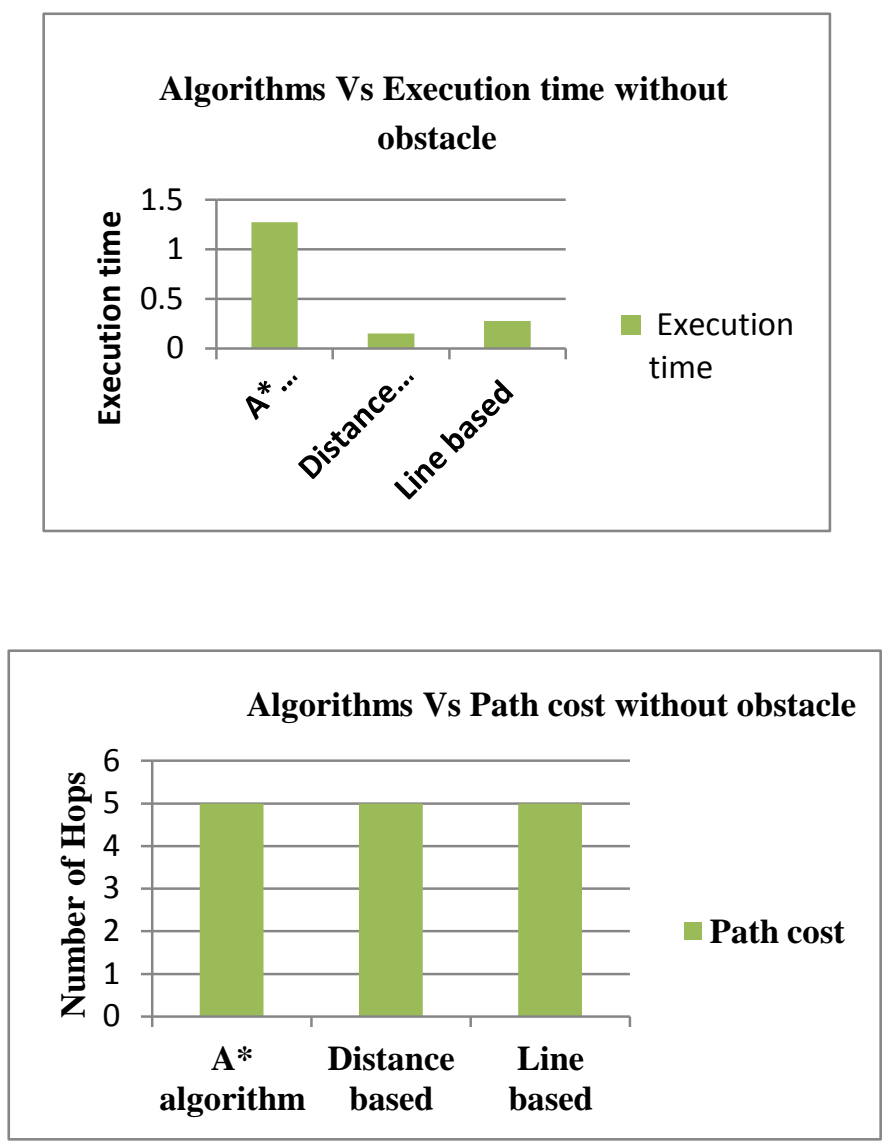

\section{obstacles in phase I Vs Execution time of algorithms}

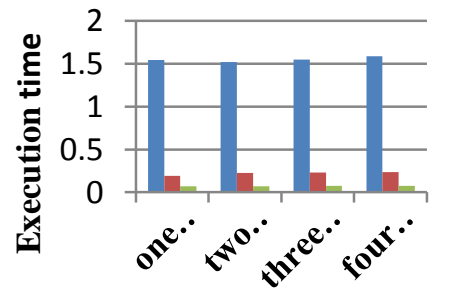

A* algorithm

Direction

based

Line based 

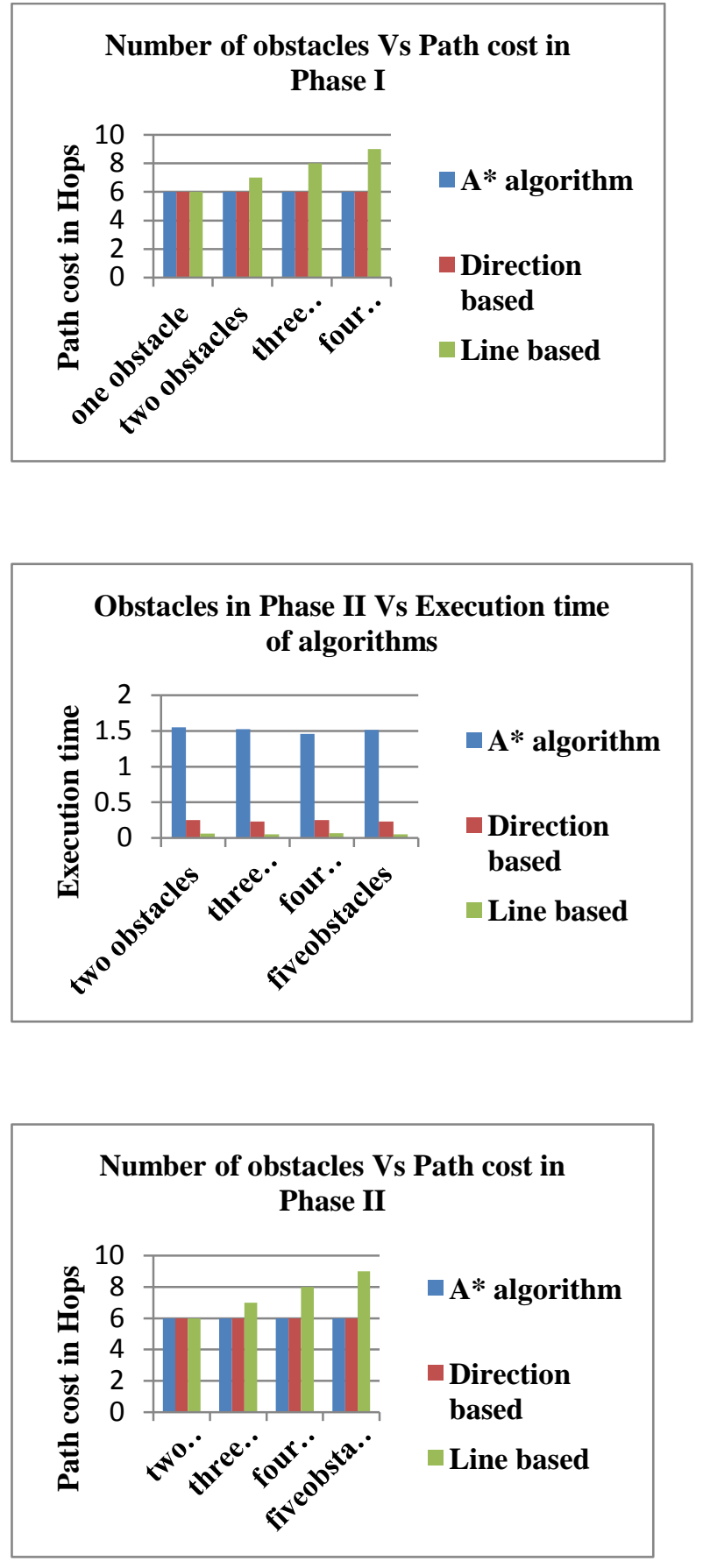

\section{Conclusion}

In order to compare the performance of the three algorithms various parameters such as execution time in calculating the path, length of the path through which some body can travel to extinguish forest fire, number of obstacles and position of the obstacles along the path are taken into consideration. Even though the simulation results are shown for a particular starting point and goal point, we have performed the comparison process by varying the starting and goal points and obtained similar results. First we have computed the execution time for finding path and length of the path (we have taken one unit as one hop moving from one cell to another cell in an 8-point neighborhood) for all the three algorithms in the same configuration space where there are no obstacles. Then we have noted the sequence of points which constituted the path for $\mathrm{A}^{*}$ algorithm without obstacles. Then we have introduced the obstacle one by one obstructing the goal along the path .From the experimental results we have found that our algorithms perform better when compared with the $\mathrm{A}^{*}$ algorithm in terms of execution time. The $\mathrm{A}^{*}$ algorithm is performing poorly in terms of execution time because of its large computational needs .Also our algorithms are a better choice for applications which requires fast path plan updates. When compared in terms of path length, direction based algorithm performs almost similar to $\mathrm{A}^{*}$ algorithm in almost all the cases whereas Line equation based algorithm lags in 80 percent of the cases but still produce a path to the goal. In all the works we have considered static obstacles and size of obstacle is same as the size of the obstacle. When our algorithms are compared direction based algorithm is best in terms of both path length as well as execution and Line equation based algorithm is best in terms of execution time for finding path. But in future we have plans to compare the performance by having dynamic obstacles with varied obstacle sizes.

\section{References}

[1] S.M.Lavalle,Planning Algorithms,Cambridge University Press,2004.

[2] R.Siegwart and I.R.Nourbaksh,Introduction to autonomous Mobile Robots,MIT Press,2004.

[3] F.Haro and M.Torres, "A comparison of Path Planning Algorithms for Omni-Directional Robots in Dynamic Environments ",

[4] M.P.Sivaram Kumar, S.Rajasekaran, "Path Planning Algorithms for Extinguishing Forest Fires using", Journal of Computing", Volume 4, issue 2, February 2012, ISSN 2151-9617, pp.108-113.

[5] Ting-Kai Wang, Quan Dang, Pei-Yuan Pan, "Path Planning Approach in Unknown Environment", International Journal of Automation and Computing", 7(3), August 2010, pp.310-316.

[6] M Seda and T Brezina, "Robot Motion Planning in Eight Directions", Proceedings of the World Congress on Engineering and Computer Science 2009 Vol II WCECS 2009, October 2009, San Francisco, USA

[7] M.P.Sivaram Kumar, S.Rajasekaran, "Line based Geometrical Path Planning Algorithm for extinguishing Forest fires", International Journal of Computer Applications", Volume 52, Issue 8, August 2012, pp.2226.

[8] Richard Fox, Antonio Garcia.Jr and Michael nelson, "A Two dimensional Path Planning Algorithm, Informal Publication.

[9] http://intelligence.worldofcomputing.net/ai-search/a-staralgorithm.html

[10] N.J.Nilson, Artificial Intelligence: A New Synthesis, Morgan Kauffman 1998. 